\title{
Retardo mental en el niño
}

Entre los órganos del ser humano que sufren deterioro más fácilmente, se encuentra el sistema nervioso, y en especial el cerebro, pues las células nobles no se regeneran. Su desarrollo, en general, es muy rápido, desde el período de embrión hasta el segundo año de vida y es por

*Unidad de Genética, Hospital Luis Calvo Mackenna. ello que cualquier desequilibrio en este lapso conducirá a una malformación, detención de crecimiento, destrucción de tejido o atrofia de su parénquima, lo que es irreparable. Su consecuencia lógica será una limitación en su capacidad funcional mayor o menor, y es lo que conocemos como retardo mental.

Este síndrome siempre fue una nebulosa de 
la medicina, sin embargo en el último decenio se le ha ido desglosando, haciendo posible la prevención y tratamiento de muchas de sus causas productoras

Dentro de los conocimientos actuales, se sabe que las causas son muy variadas, y es por ello que son dificiles de clasificar. ${ }^{1}$ Si utilizamos el criterio etiológico, los hay genéticos, ambientales y otros aún desconocidos. Lo cierto es que en muchos retardos mentales desempeña su papel uno o los dos factores antes nombrados, siendo dificil su ubicación exacta. Por otro lado, una misma noxa puede dar distinto efecto en el individuo, dependiendo del momento en que actúe, de la intensidad con que lo haga y del lapso de tiempo que prolongue su efecto, y así podrá variar desde la normalidad hasta un daño profundo y aun la muerte. ${ }^{2}$ Utilizando un criterio de acuerdo a la cronología del daño, se les clasifica en prenatales, del parto y postanatales, lo que también tiene sus ventajas, especialmente cuando sea posible su prevención. Existen noxas que actúan precozmente, como son las de tipo genéticas; otras actúan tardíamente, como serían las funcionales y otras, en cualquier período, como son las infecciones, tóxicas, etc. En fin, usando criterio pragmático se les puede clasificar en causas definitivas de daño cerebral, como serían las cromosomopatías y en causas sólo potenciales, siendo un ejemplo la rubéola, las alteraciones placentarias, etc.

Nos referiremos a retardo mental si el coeficiente intelectual se encuentra bajo lo normal, sea cual sea la intensidad de él, ya que muchos autores sólo hacen mención de aquellos profundos o muy significativos, lo que a nuestro juicio es un error. Todo individuo con una potencialidad limitada es un retardado mental y esto es válido bajo un CJ de 80 y bajo un CD de 80 en la escala de Gesell.

La clasificación de más utilidad para el médico es aquella que imbrica la etiología con el momento de aparición del daño, pues mientras más tardía sea la producción retardo mental, mayores serán las probabilidades de prevención y tratamiento oportunos. Es por lo tanto responsable directo el obstetra, como el neonatólogo y luego el pediatra, de la pesquisa precoz de esos factores que luego detallaremos. ${ }^{4}$ Es de todos conocido que mientras mayor sea el niño afectado, al ser examinado más difícil será encontrar la noxa productora, especialmente si se trata de causas ambientales.

\section{CAUSAS GENETICAS}

Son todas aquellas ligadas al DNA, sea que se reciba como tara de los progenitores y serán hereditarias propiamente tales, o sea que aparezca bruscamente como una mutación o aberración cromosómica.

\section{A. Hereditarias}

I. Monogénicas, siguen las leyes de Mendel, siendo por tanto dependientes de un gen alterado $y$ trasmitiéndose en forma autosómica dominante, recesivas o ligadas al cromosoma $\mathrm{X}^{3}$

1. Autosómicas dominantes. Todas ellas de penetrancia y expresividad variable, pero alta. Ello quiere decir que no siempre un enfermo demuestra todos los signos de la enfermedad y por ello no siempre presenta retardo mental. Entre éstas podemos nombrar la acondroplasia, Ehler-Danlos, ictiosis con RM, facomatosis como el Sturge-Weber, enfermedad de Crouzon, acrocefalosindactilia o $S$. de Apert, etc.

2. Autosómicas recesivas. De gran importancia, ya que la detección de portadores (heterocigotos), podrá evitar la producción de esta patología y prevenir su repetición, por medio del consejo genético, y en fin tratar precozmente a los afectados. En este rubro se encuentran la mayoría de los errores de metabolismo que pueden dar retardo mental. Así tenemos la fenilquetonuria, que ya se ha detectado en nuestro país, la mayoría, de las mucopolisacaridosis y mucolipidosis, glicoesfingolipidosis, homocistinuria, hiperglicinemias, galactosemias, etc. Recordemos que hoy día puede hacerse el diagnóstico prenatal, en el líquido amniótico y hacer screening (para muchas de ellas) en los recién nacidos, buscando posibles afectados. Vale la pena mencionar el test de cloruro férrico para la fenilquetonuria y la enf. con orina olor a jarabe de arce, la dinitrofenilhidracina, que confirma la anterior, la metacromasia en mucopolisacaridosis al igual que el test de azul de toluidina, el test de Benedict para la galactosemia y otros más sofisticados con determinaciones enzimáticas o con cultivos de fibroblastos especialmente para el diagnóstico prenatal. La incompatibilidad de grupos sanguíneos tanto $R h$, como para grupos clásicos puede incluirse en este acápite y en las que se usará el test de Coombs. la tasa de aglutininas y la bilirrubinemia para prevenir un posible daño cerebral. Debemos 
mencionar aquí ciertos tipos de cretinismo que son hereditarios y que pueden conducir a daño cerebral. Los ejemplos se multiplican cada día y es inoficioso hacer listas de nuevas enfermedades que se encuadran en este rubro, ya que la literatura los repite en muchos artículos y libros de medicina. ${ }^{2-5-6}$ Existen más de 50 errores de metabolismo, que provocan retardo mental y en los que hoy día puede detectarse a los heterocigotos (portadores). Cerca de 100 de ellos pueden ubicarse en forma prenatal. En general, los errores del metabolismo de los aminoácidos y de los hidratos de carbono son los que tienen más posibilidades de iratamiento. ${ }^{7}$

Entre las enfermedades de herencia recesiva con retardo mental y en las que no se ha probado error metabólico mencionemos, entre otras, los síndromes de Smith-Lemnli-Opitz, Wiedeman-Beckwith; Sjogren-Larsson, LaurenceMoon-Biedl, Brocq, Hallerman-Streiff, Seckel, etc. Debemos hacer aquí especial mención de un retardo mental familiar, sin otras malformaciones y en el que por el momento no se ha encontrado una verdadera causa y en el cual se incluye muchos pedigree.

3. Ligadas al cromosoma $X$. Sin entrar en detalles de sus formas hereditarias nombraremos al síndrome de Hurler (tipo de mucopolisacaridosis), sindrome de Borjeson, estenosis congénita del acueducto de Silvio, hipertelorismo con hipospadia, algunos tipos de microftalmia, Enf. de Dreifuss, síndrome de Van den Bosch, etc., todas ellas pueden llegar al retardo mental.

\section{Enfermedades de herencia poligénica, es} decir, que dependen de varios genes y en las cuales influye también el medio ambiente, para hacer posible su aparición. No siguen las leyes de Mendel, sino leyes que se conocen sólo en forma empírica. A mayor gravedad de la lesión hay mayor riesgo de repetición, igual cosa sucede si el padre y el hijo están afectados, o si se afecta el sexo menos frecuente. Aquí se incluyen muchas malformaciones del sistema nervioso $y$ otras, que incluyen el retardo mental. Entre las enfermedades que hoy se postulan con este tipo de herencia se encuentra la epilepsia, la esquizofrenia, etc.

\section{B. Cromosómicas}

La mayoría de ellas son esporádicas y muy rara vez son capaces de reproducirse y perpetuar el retardo mental (como sucede con la mujer que tiene trisomia 21). Ocasionalmente los padres normales pueden ser portadores de una aberración cromosómica balanceada, vale decir, tienen su material genético completo, pero desarreglado, y ellos pueden dar hijos con exceso o falta de parte de ese material y serán anormales y con daño cerebral.

I. Alteraciones autosómicas. Cada día se encuentran nuevas variantes y que son responsables de retardos mentales mayores o menores. Las trisomias clásicas son ya muy conocidas. Entre ellas está la trisomia 21, la trisomia 13 y la 18; hoy se conocen los casos mosaicos con poblaciones normales y que muchas veces dan cuadros clínicos intermedios; finalmente las trisomias parciales (parte de un cromosoma triplicado) o las delecciones (monosomias parciales) han proliferado en la literatura con las nuevas técnicas de estudios cromosómicos. En este tipo de alteraciones sólo el consejo genético a los padres puede ayudar a evitarlos; en los países en que el aborto está legalizado, es el estudio prenatal en los fetos de alto riesgo lo que decide la situación. El conocimiento exacto de las posibilidades de repetición son indispensables para su prevención.

II. Alteraciones gonosómicas. Es conocido que los individuos que presentan en su fórmula gonosómica un cromosoma $\mathrm{X}$ extra, presentan, en cierto porcentaje, retardo mental, el que va en aumento proporcional al mayor número de cromosomas $\mathrm{X}$ extras, igual cosa vale para las alteraciones estructurales de este gonosoma o para la ausencia de uno de ellos, como sucede en el sindrome de Turner. Se ha descrito también retardo mental en alteraciones numéricas y morfológicas del cromosoma $\mathrm{Y}$. Al igual que en el grupo anterior, los casos mosaicos con poblaciones celulares normales, también presentan en cierta proporción un daño cerebral.

Existe un número de enfermedades en que se sospecha una participación hereditaria, pero que aún no ha sido posible probarlo. A ellas las incluiremos en un acápite aparte, al final de nuestra clasificación.

\section{CAUSAS AMBIENTALES}

Como es lógico pensar, son adquiridas por el feto o el niño en desarrollo, en cualquier momento de su vida. Ellas son más fáciles de prevenir. $\mathrm{Al}$ igual que el grupo anterior pueden ser causas 
definitivas o sólo potenciales de daño cerebral, dependiendo del momento, intensidad y/o prolongación de su acción el que el daño sea mayor o menor. ${ }^{8}$

Tanto es así que a veces pasa inadvertida su funesta presencia y sólo se encuentra posteriormente con las secuelas. Es frecuente en nuestro medio que la anamnesis sea dificil y muchas veces negativa, por ignorancia o incultura; únicamente mejorando estos defectos podremos evitar noxas deletereas.

\section{A. INFECCIONES}

1. Virus. Existen algunos definitivamente comprobados, como es el de la rubéola en los primeros cuatro meses de gestación y se acompaña además de otras malformaciones. El citomegalovirus puede dar una variada gama de retardos mentales con microcefalia, y el virus herpético, presumiblemente adquirido en el momento del nacimiento. Otros como el Coxsackie B, de la gripe y ECHO son potenciales. La encefalitis viral con el virus equino, San Luis, Venezuela, etc., y postinfectocontagiosas también son potenciales de esta patología (sarampión, viruela, etc.).

II. Bacterios. Los efectos se presentan de los diverses tipos de meningitis de bos lactantes, especialmente los gram negativos. La resistencia adquirida a los antibióticos y el diagnóstico tardio son los causantes de las nefastas consecuencias. Incluimos la sepsis en este rubro. La tuberculosis razas predispuestas y especialmente paises en desarroflo llega a produscir esta securela.

I11. Espäroqueta sifilitica, con efectos inmediatos o tandios.

IV. Parásitos. En nuestro medio es especialmente notoria la toxoplasmosis y la enfermedad de chagas, pues la triquinosis, amebiasis cerebral y otras son muy escasas.

V. Hongos. Afortunadamente en nuestro país no son causa de daño cerebral.

\section{B. Agentes químicos}

I. Elementos. En primer lugar mencionemos la intoxicación por plomo, que lleva a alteraciones neurológicas e incluso a retardo mental. Se puede titular su nivel sanguíneo y las protoporfirinas en gróbulos rojos, para encontrar posibles afectados. El talio, cadmio, arsénico y mercurio son potencialmente productores de retardo mental. Por otro lado, carencia de algunos elementos con el Yodo llevan a daño cerebral (creatinismo). Se cree que microelementos como $\mathrm{Mg}$ también sería causa.

II. Compuestos. Monóxido de carbono encabeza la lista, el LSD ha sido demostrado como causante y el metanol, etc.

III. Toxinas. Altamente sospechosos aunque no comprobados en forma definitiva se encuentra el botulismo, tétano y difteria de la embarazada."

IV. Metabólicas. Conocidos son los efectos de la hipoglicemia en el recién nacido, la hipernatremia del lactante, el kernicterus y la desnutrición grave.

\section{Agente físico}

1. Traumatismo, que abarcan desde el momento del parto a aquellos producidos posteriormente en la vida del niño y que por hemorragia, laceración de tejidos cerebral y cicatrices posteriores llevan al retardo mental.

II. Radiaciones, sea de rayos Roentgen o de cuerpos radiactivos tan comúnmente usados hoy día en diagnóstico y tratamiento. Es el feto el más sensible a esta noxa, pero dependiendo de la dosis incluso en edades de lactancia pueden ser perniciosas.

\section{ANOXIA}

Por su importancia y variada etiología vale la pena colocarla como un acápite aparte. La encontraremos tanto en el embarazo como en el parto y en edades posteriores. Se imbrica con muchas de las etiologias ya nombradas, siendo difícil separarla. Una intoxicación por metahemoglobina, anemia aguda intensa de la madre, una mala implantación placentaria o placenta patológica, toxemia gravídica intensa que cause dificultad en la hematosis fetal, etc., son cronológicamente de origen prenatal: durante el parto, son temidos los sufrimientos fetales y es el obstetra el que tiene en sus manos el evitarlo. En el período postnatal, lactancia e infancia habían muchas posibilidades de anoxia, desde la inmersión en el agua hasta una infección del sistema nervioso central o traumatismos, y en los que una de las medidas fundamentales que se abocará el pediatra es la buena oxigenación. Recordemos especialmente la prematurez, la 
aspiración de alimentos, los accidentes vasculares, alteraciones hematológicas y muchas otras que siempre están en el tapete de la pediatría. Son éstos dificiles de rastrear en la amnesis de un retardo mental.

\section{E. INMUNOLÓgicas}

Reacciones a fármacos o alimentos para un cerebro en formación, pueden terminar en un retardo mental. La encefalopatía postinmunización también ha sido descrita, ${ }^{1}$ y puede presentarse, aunque muy rara vez, con cualquier tipo de vacuna. Aquí puede colocarse también la enfermedad hemolítica del recién nacido. Procesos inmunitarios con destrucción de la glándula tiroides (tiroiditis) conducen a retardo mental.

\section{F. Funcionales}

Falta de estímulo o deprivación materna, en la cual el potencial cerebral no estimulado a su debido tiempo, puede no desarrollarse íntegramente, conduciendo a un retardo mental. Al autismo y otras minusvalías cerebrales se les imputa este origen.

\section{DESCONOCIDAS}

Este rubro, que ha ido disminuyendo en los últimos años, ha ido pasando a los dos anteriormente mencionados. Sin embargo, existen síndromes conocidos que no han sido definitivamente comprobados. Entre ellos tenemos:

1. Síndrome como el leprechaunismo, la progeria, Cornelia de Lange, de Rubinstein, Silver, Russel, Seckel, etc. Posiblemente tengan un componente genético, pero al ser esporádicos, con las técnicas actuales, no es posible comprobar su etiología.

2. Tumores, especialmente primarios del sistema nervioso central, o bien metastásico que comprimen y destruyen tejido cerebral y provocan el retardo mental. La alteración cromosómica encontrada no se sabe si es causa o efecto.
3. Degenerativas. Hay destrucción de las vainas de mielina. Ejemplo son la enf. de Cockayne, enf. de Schilder que es rápidamente progresiva, la enf. de Hiller, de Alper y muchas otras. Por supuesto que para éstas no existe tratamiento sino paliativo.

Hemos hecho un repaso rápido del origen del retardo mental en el niño, dividiéndolos en grandes grupos de manera didáctica y cuya finalidad es facilitar su búsqueda, tratamiento precoz y consejo genético a los padres y familiares de esta agobiante patología. Algunos de estos enfermos no tienen tratamiento, pero la gran mayoría, al contrario de lo que generalmente se piensa, pueden rendir bastante más que dejados sin tratamiento; sólo unos pocos son recuperables ad integrum, si la terapia es oportuna. La mayoría de ellos requieren de un conjunto de especialistas, para su terapia armónica. Instituciones especializadas con este objeto son ideales y necesarias, y su financiamiento debe ser aportado por la sociedad entera, ya que ninguno de nosotros está libre de las múltiples noxas productoras de este síndrome, que se cierne sobre nuestra descendencia. El aumento de la cultura de nuestro pueblo, de los conocimientos y prácticas médicas de nuestros profesionales y la tecnología paramédica serán los principales factores en la prevención y tratamiento de los afectados.

\section{REFERENCIAS}

1 Carter, C.H. Retraso mental en el niño. Editorial Pediátrica, España, 1973.

2 Gardner, L.I. Endocrine and Genetic deseases of childhood Saunders Co., 1975

3 McKustck, V.A. Mendelian inheritance in man. The Johns Hopkins Press, 1968

4 Babson, S.G. and R.C. Benson. Managment of high risk pregnancy and intensive care of the neonate. Mosby Co., 1971

5 Harris, M. Early diagnosis of human genetic defects. Fogarty Int. Center Proc., 1970.

- Milunsky, A. The prevention of genetic disease and mental retardation. Saunders Co., 1975

7 Nyhan, W. Amino acid metabolism and genetic variation. McGraw Hill Co., 1967.

-Waisman, H. and G. Kerr. Fetal growth and development. McGraw Hill Co., 1968. 